\title{
The comparison of triceps-reflecting anconeus pedicle and olecranon osteotomy approaches in the treatment of intercondylar fractures of the humerus
}

\author{
İbrahim Azboy, M.D., ${ }^{1}$ Mehmet Bulut, M.D., ${ }^{1}$ Cahit Ancar, M.D., ${ }^{1}$ Abdullah Demirtaş, M.D., ${ }^{2}$ \\ Emin Özkul, M.D., ${ }^{1}$ Mehmet Gem, M.D., ${ }^{1}$ Hilmi Karadeniz, M.D., ${ }^{3}$ Hüseyin Arslan, M.D. ${ }^{1}$
}

${ }^{1}$ Department of Orthopaedics and Traumatology, Dicle University Faculty of Medicine, Diyarbakır, Turkey

${ }^{2}$ Department of Orthopaedics and Traumatology, Göztepe Training and Research Hospital, İstanbul, Turkey

${ }^{3}$ Department of Orthopaedics and Traumatology, Bahçelievler Medikal Park Hospital, İstanbul, Turkey

\begin{abstract}
BACKGROUND: This study aimed to evaluate the functional outcomes of patients with intra-articular distal humerus fractures treated with triceps-reflecting anconeus pedicle (TRAP) and olecranon osteotomy.

METHODS: Forty patients with intra-articular distal humerus fractures were retrospectively analyzed. TRAP approach was used in 22 patients ( 12 males, 10 females; mean age 37.8 years, range 17-70), and olecranon osteotomy in 18 patients ( 11 males, 7 females; mean age 35.4 years, range 18-62). Fractures were classified using the AO/ASIF classification. Functional results were evaluated with the Mayo elbow performance score (MEPS) and the Disabilities of Arm, Shoulder and Hand (DASH) questionnaire score.

RESULTS: The overall mean arc of elbow motion was $108^{\circ}$ (range $70^{\circ}-140^{\circ}$ ) in the TRAP group, whereas that of the olecranon osteotomy group was $98^{\circ}\left(\right.$ range $\left.70^{\circ}-115^{\circ}\right)$. A significant difference was observed between the two groups in terms of overall mean arc of elbow motion $(p=0.038)$. There were no significant differences noted between the two groups in terms of mean MEPS and DASH scores $(p=0.412, p=201$, respectively). The overall complication rate was $27.2 \%$ in the TRAP group and $55 \%$ in the olecranon osteotomy group.
\end{abstract}

CONCLUSION: TRAP is a succesful approach in the treatmet of intra-articular distal humerus fractures that provides better arc of elbow motion, reduces complications and reoperation rates.

Keywords: Distal humerus; internal fixation; intra-articular fracture; olecranon osteotomy; TRAP.

\section{INTRODUCTION}

Intra-articular fractures of the distal humerus (AO type C) constitute $1 \%$ of all fractures in adults. ${ }^{[1]}$ These fractures remain one of the most difficult fractures to treat. ${ }^{[2]}$ Anatomic reconstruction of the articular surface and stable internal fixation are the key factors for successful functional outcomes. ${ }^{[3]}$ Adequate exposure of the articular surface is a prerequisite

Address for correspondence: İbrahim Azboy, M.D.

Dicle Üniversitesi Tıp Fakültesi, Ortopedi ve Travmatoloji Anabilim Dalı, 21100 Diyarbakır, Turkey

Tel: +90 4I2 - 248800 I E-mail: ibrahimazboy@hotmail.com

Qucik Response Code Ulus Travma Acil Cerrahi Derg 2016;22(I):58-65

doi: $10.5505 /$ tjtes.20I5.42948

Copyright 2016

TJTES for anatomic reconstruction and stable fixation of these fractures. ${ }^{[4-6]}$ To better visualize the articular surface, olecranon osteotomy, ${ }^{[7-9]}$ Bryan-Murrey (triceps reflecting), ${ }^{[10]}$ triceps splitting (Campbell), ${ }^{[1]}$ and triceps-reflecting anconeus pedicle (TRAP) ${ }^{[12]}$ approaches have been used.

Olecranon osteotomy is the most frequently preferred surgical approach that provides excellent exposure. ${ }^{[1,14]}$ However, olecranon osteotomy has disadvantages such as delayed union, nonunion, avascular necrosis, heterotrophic ossification, and prominent hardware..$^{[7-9,14,15]}$

TRAP approach, as defined by O'Driscoll et al., ${ }^{[12]}$ is an alternative approach in these fracture patterns. This approach is a combination of modified Kocher and Bryan-Morrey, mobilizes the triceps and anconeus muscle of the posterior humerus, and also provides adequate exposure of distal humerus. This approach avoids osteotomy, preserves nerve supplies of anconeus, and has no hardware related problems. On 
the other hand, some disadvantages with this approach have been reported, such as limited exposure of the articular surface, longer duration of surgery, and weakness of the triceps muscle. ${ }^{[13,16]}$

The indications and superiority of these two techniques are a question of debate. In the literature, there are limited numbers of studies on this issue. ${ }^{[16,17]}$ The current study aimed to compare the TRAP approach with olecranon osteotomy regarding their effects on the functional results of intra-articular distal humerus fractures treated with open reduction and internal fixation (ORIF).

\section{MATERIALS AND METHODS}

Forty patients who were treated with ORIF with the diagnosis of adult distal humerus intra-articular fracture according to AO/ASIF classification ${ }^{[18]}$ between 2006 and 2012 were retrospectively evaluated. TRAP approach was used in twenty-two patients (TRAP group; 12 males, 10 females; mean age 37.8 years, range 17-70 years), and olecranon osteotomy in eighteen patients (Olecranon osteotomy group; II males, 7 females; mean age 35.4 years, range 18-62 years). The preference of surgical approach was made by surgeon's discretion. According to AO/ASIF classification, there was a $\mathrm{Cl}$ fracture in six patients, $\mathrm{C} 2$ fracture in 15 patients, and $\mathrm{C} 3$ fracture in 19 patients (Table I). According to the Gustilo-Anderson classification, ${ }^{[19]}$ there was a Grade I open fracture in four patients and Grade II open fracture in 3 patients (Table I). Patients with the following were excluded from the study; pathologic fractures, rheumatoid arthritis treated with corticosteroids for a long period of time, associated ipsilateral forearm fractures, functional loss prior to the fracture, and inadequate follow-up.
The mechanism of injury included sixteen patients of fall, three cases of traffic accidents, two cases of sports injuries, one case of firearm injury in TRAP group; and 10 patients of fall, seven cases of traffic accidents, and one case of sports injury in the olecranon osteotomy group. Six patients (I5\%) had accompanying fractures and two of them had concomitant head and thorax injury.

\section{Surgical Technique}

All patients were prepared in the supine position and tourniquet was applied. A straight posterior longitudinal skin incision was used just lateral to the olecranon tip. Then, ulnar nerve was identified proximally and released distally.

In the TRAP group, the TRAP approach was used for exposure of the elbow which was described by O'Driscoll et al. ${ }^{[12]}$ The anconeus muscle was subperiosteally separated from the ulna laterally, preserving the integrity of lateral collateral ligament complex and annular ligament. Along with the anconeus lateral side of the triceps, and then, the medial side were reflected from the olecranon (Fig. I). While the triceps was removed from its insertion, the portion $1 \mathrm{~cm}$ distal to olecranon tip was marked with a drill to be used as a guide during closure. The posterior capsule was incised and the dissection was carried out proximally. The fragments were reduced with temporary K-wires. Parallel plating was performed in fourteen patients $(63.6 \%)$ and orthogonal plating was performed in 8 (36.4\%). Then, the triceps was reattached with interrupted number- 2 Ethibond suture by using the drillholes through the bone in the olecranon, and the wound was closed as usual.

In the olecranon osteotomy group, an apex distal, chevronshaped osteotomy was preferred. The osteotomy was per-

Table I. Data summary of patients

\begin{tabular}{|c|c|c|c|}
\hline Parameters & TRAP $(n=22)$ & Olecranon osteotomy $(n=18)$ & $\mathbf{p}$ \\
\hline Male/female ratio (no. of patients) & $12 / 10$ & $10 / 8$ & 0.612 \\
\hline Mean age (year) (range) & $37.8(17-70)$ & $35.4(18-62)$ & 0.791 \\
\hline Gustillo-Anderson classification (no. of patients) & & & 0.782 \\
\hline Closed & 18 & 15 & \\
\hline Type I open & 2 & 2 & \\
\hline Type 2 open & 2 & 1 & \\
\hline Type 3 open & 0 & 0 & \\
\hline Mean time to surgery (day) (range) & $3.8(1-12)$ & $3.1(2-11)$ & \\
\hline Mean follow-up (month) (range) & $36(16-74)$ & $28(14-72)$ & \\
\hline AO/ASIF classification (no. of patients) & & & 0.258 \\
\hline $\mathrm{Cl}$ & 4 & 2 & \\
\hline C II & 8 & 7 & \\
\hline C III & 10 & 9 & \\
\hline
\end{tabular}

TRAP: Triceps-reflecting anconeus pedicle; OO: Olecranon osteotomy. 


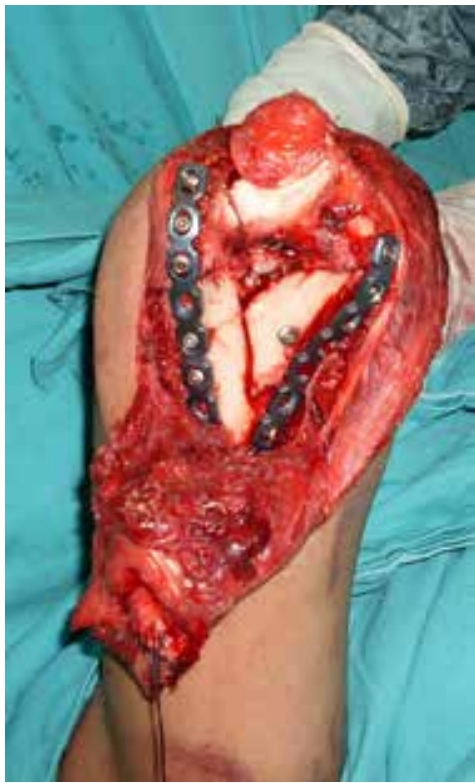

Figure 1. Intraoperative view of a patient after orthogonal plating using TRAP approach in which olecranon fully skletonized.

formed approximately $2 \mathrm{~cm}$ distal to the tip of olecranon (Fig. 2a). An oscillating saw was used to start osteotomy. An osteotome was used to complete osteotomy by levering the osteotome proximally. These maneuver results in cracking the subchondral bone and cerates uneven surface that facilitates reduction. The posterior elbow capsule was then incised and the joint was reached (Fig. 2b). The fragments were reduced with temporary K-wires. Parallel plating was performed in thirteen patients (72\%) and orthogonal plating was performed in 5 (28\%). The proximal fragment of the olecranon was repositioned. Fixation was obtained with a tension band over a I cancellous screw, and the wound was closed as usual.

In the TRAP group, an iliac autograft was used in one patient for the bone defect in the supracondylar region. In twelve patients (30\%) (7 and 5 patients in the TRAP and olecranon osteotomy groups, respectively) ulnar nerve was in contact with the medial plate in the cubital tunnel, hence subcutane-
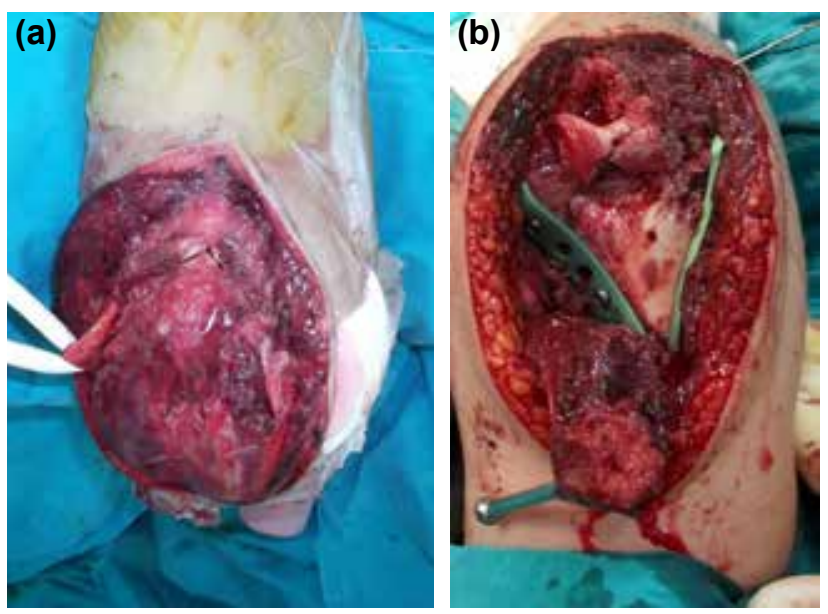

Figure 2. Intraopretive view of a patient shows apex distal, chevron-shapped osteotomy (a); after parallel plate application (b). ous anterior transposition of the ulnar nerve was performed in these patients. Three senior authors (HA, MB, IA) performed the operations.

\section{Postoperative Care and Follow-up}

Standard postoperative rehabilitation programme was used for ROM exercises applied by a physiotherapist for both groups. In both groups, a removable long arm splint was used for two weeks. Active assisted elbow movements were started on the second postoperative day. In the olecranon osteotomy, active elbow motion was started at two weeks postoperatively, whereas in the TRAP group, active elbow extension was prohibited until six weeks postoperatively to avoid undue stress on extensor mechanism repair. The patients were followed-up on the first, sixth and twelfth months after surgery.

The patients were radiologically evaluated with anteroposterior and lateral radiographies until fracture union was fully observed. Triceps strength was graded according to the system given by Wolfe et al. ${ }^{[20]}$ at the final follow-ups, the functional evaluation of the patients were carried out with goniometric measurement of the range of motion in the elbow joint, Mayo elbow performance score (MEPS), ${ }^{[21]}$ and Disabilities of Arm, Shoulder and Hand (DASH) questionnaire. ${ }^{[22]}$ The MEPS score is based on a 100-point scale which evaluates the pain relief, function, motion and stability of elbow. The MEPS falls in to four grades: $\geq 90$, Excellent; 75-89, Good; 60-74, Fair; $<60$, Poor. Mean duration of follow-up of all patients was 34 months (range 14-78 months).

\section{Statistical Analysis}

Data were analyzed using the Statistical Package for Social Sciences 18.0 (SPSS Inc., Chicago, IL, USA) software. Statistical significance between variables of both groups were analyzed with student's t, chi-square, Fischer's exact, and MannWhitney $U$ tests. A p value $<0.05$ was accepted as significant.

\section{RESULTS}

Mean duration of follow-up was 36 months (range 16 to 74 months) in TRAP group, and 28 months (range 14-72 months) in the olecranon osteotomy group.

No significant differences were observed between the groups in terms of gender, age, type of fracture, time to operation, or presence of open or closed fractures $(p<0.05)$. All fractures healed at the end of the follow-up period.

The overall mean arc of elbow motion was $108^{\circ}$ (range $70^{\circ}-140^{\circ}$ ) in the TRAP group (Fig. 3), whereas that of the olecranon osteotomy group was $98^{\circ}$ (range $70^{\circ}-115^{\circ}$ ) (Fig. 4) . A significant difference was observed between the two groups in terms of overall mean arc of elbow motion $(p=0.038)$ (Table 2). No patients had limitation of forearm 

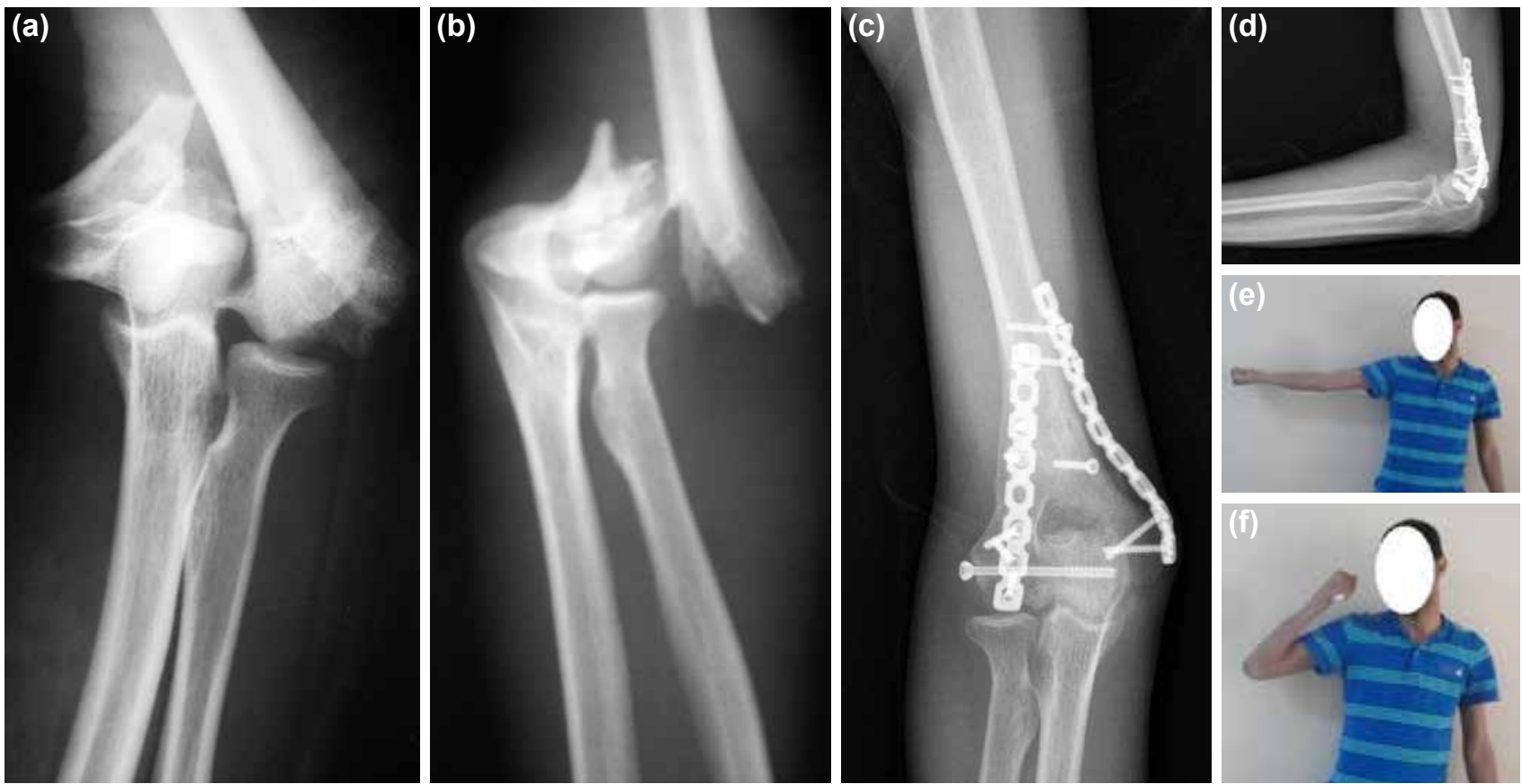

Figure 3. Preoperative X-rays (anteroposterior and lateral views) of the elbow shows intra-articular fracture of distal distal humerus (a, b); after orthogonal plate fixation using the TRAP approach, at 56 months of follow-up X-rays (anteroposterior and lateral views) shows fracture union $(\mathbf{c}, \mathbf{d})$; functional view of the patient $(\mathbf{e}, \mathbf{f})$.

pronation-supination. Range of motion improved in the first sixth months.

At the final control of the patients, mean MEPS was 85.9 (range 55-100) in the TRAP group, whereas that of the olecranon osteotomy group was 83.5 (range 55-100). Although mean MEPS was higher in the TRAP group, no significant difference was noted between the two groups $(p=0.412)$ (Table 2). Mean q-DASH score was $I 5.6$ (range, 0-48) in the TRAP group, whereas that of the olecranon osteotomy group was 20.I (range 4-57). Although mean q-DASH score was higher in the TRAP group, no significant difference was detected between the two groups $(p=0.201)$ (Table 2$)$. No significant difference was found between the groups in terms of fixation technique preferred for distal humerus fracture when considering functional outcomes $(p<0.05)$.

\section{Complications}

The overall complication rate was $27.2 \%$ in the TRAP group and $55 \%$ in the olecranon osteotomy group.

In the TRAP group, ulnar nerve paresthesia developed in two patients $(9.1 \%)$, which resolved spontaneously in three months. Triceps muscle weakness was observed in two patients $(9.1 \%)$. One patient $(4.5 \%)$ had varus deformity 10 degrees, but without any interfering in elbow function. One patient (4.5\%) developed deep infection at sixth month. The patient healed with debridement and antibiotic treatment. However, avascular necrosis developed in the follow-up and fair result was obtained in this patient. Triceps muscle rupture was not observed in any patient.

In the olecranon osteotomy group, implant irritation was ob-

Table 2. Mean arc of elbow motion and functional outcomes at latest follow-up

\begin{tabular}{lccc}
\hline Parameters & TRAP $(\mathbf{n}=\mathbf{2 2})$ & Olecranon osteotomy $(\mathbf{n}=18)$ & $\mathbf{p}$ \\
\hline Mean arc of elbow motion (range) & $108(70-140)$ & $98(70-115)$ & 0.038 \\
Mean DASH score (range) & $15.6(0-48)$ & $20.1(4-57)$ & 0.201 \\
Mean MEPS score (range) & $85.9(55-100)$ & $83.5(55-100)$ & $6(33.3)$ \\
Excellent, $\mathrm{n}(\%)$ & $10(45.5)$ & $8(44.4)$ \\
Good, $\mathrm{n}(\%)$ & $8(36.4)$ & $3(16.7)$ \\
Fair, $\mathrm{n}(\%)$ & $3(13.6)$ & $1(5.6)$ \\
Poor, $\mathrm{n}(\%)$ & $\mathrm{I}(4.5)$ & 0.412 \\
\hline
\end{tabular}

TRAP: Triceps-reflecting anconeus pedicle; DASH: Disabilities of arm, shoulder and hand; MEPS: Mayo elbow performance score. 

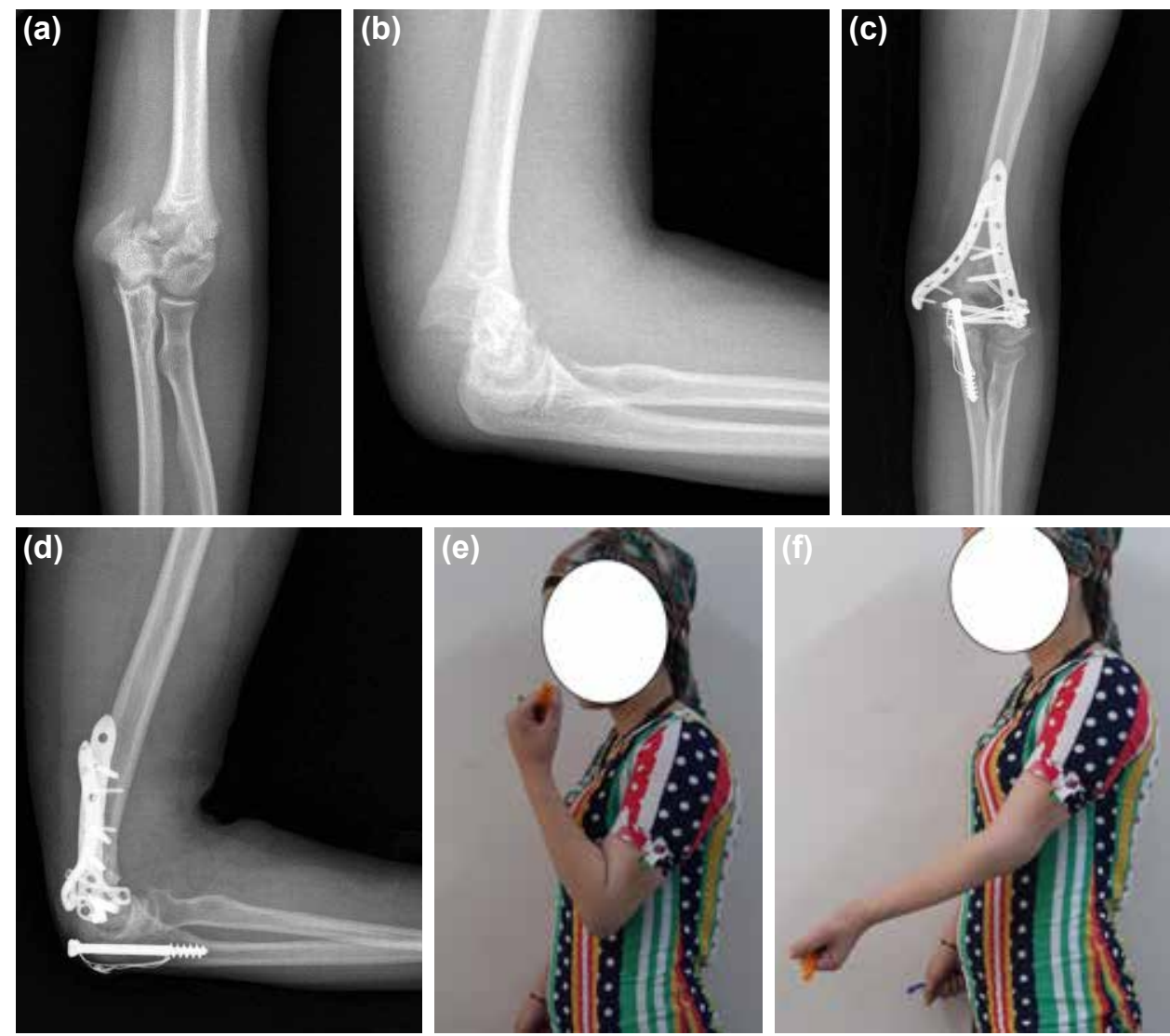

Figure 4. (a, b) Preoperative X-rays (anteroposterior and lateral views) of the elbow shows intraarticular fracture of distal distal humerus; (c, d) after parallel plate fixation using olecranon osteotomy approach, at 19 months of follow-up X-rays (anteroposterior and lateral views) shows fracture union; (e, f) functional view of the patient.

served in four patients (22\%). After removal of the implants in the olecranon, the symptoms resolved in these patients. In two patients ( $11 \%)$, a delay in union of the olecranon osteotomy site was observed; however, union was achieved without need for additional surgery. Union was achieved in olecranon osteotomy site in other patients. Nonunion of distal humerus fracture was developed in one patient (5.5\%) and a second surgery was performed. Union was achieved by harvesting iliac crest autograft and reosteosynthesis. Ulnar nerve paresthesia developed in two patients (II\%) and resolved spontaneously in three months. Triceps muscle weakness was observed in one patient (5.5\%).

\section{DISCUSSION}

The current study revealed that the TRAP method is more successful than olecranon osteotomy in terms of overall mean arc of elbow motion $(p=0.038)$. When $q$-DASH scores and MEPS scores were examined, it was observed that the results were better for the TRAP group, but there were no statistically significant difference between the groups, $(p=0.234)$ $(p=0.403)$ respectively.

The main purpose in the treatment of intra-articular distal humerus fractures is to achieve perfect anatomical restoration of the articular surfaces, maintain stable fixation and allow early full rehabilitation. ${ }^{[23,24]}$ Perfect exposure of the fracture is a key factor that allows restoration of articular surfaces. Thus, many approaches were defined, such as olecranon osteotomy, triceps reflecting, triceps splitting, and TRAP approaches. ${ }^{[7,10-12]}$

Olecranon osteotomy provides the most extensive exposure of the distal humerus. ${ }^{[13]}$ On the other hand, delayed union, nonunion, necessity of implant use to repair osteotomy, and prominent hardware that leads to a second surgery are among the disadvantages. ${ }^{[7-9,14,15,23,24]}$ Furthermore, nerve supplies of the anconeus muscle might be damaged, as this muscle participates in the dynamic stabilization of the elbow joint, this may cause elbow instability. ${ }^{[23]}$

Wilkinson et al. ${ }^{[13]}$ have compared the triceps split, TRAP, and olecranon osteotomy techniques in a cadaveric study. They have found that these techniques demonstrate the joint surfaces at a rate of $35 \%, 46 \%$, and $57 \%$, respectively. The authors have stated that the best exposure was achieved with the olecranon osteotomy approach $(57 \%)$, but no statistically significant difference was detected between the TRAP 
and olecranon osteotomy approaches. We should state that the exposure was better in the olecranon osteotomy group. However, we observed that increasing elbow flexion provides sufficient exposure in the TRAP group, which enables restoration of articular surfaces and stabilization of fracture. Therefore, we believe that relatively less extensive visualization of the distal humerus is not an important drawback to the TRAP approach.

Triceps-elevating exposures were generally claimed with the weakness of extension or rupture of triceps. ${ }^{[26]}$ Ozer et al. ${ }^{\left[{ }^{[1]}\right]}$ have used TRAP approach in eleven patients with $A O$ type $C$ fractures. They have performed an isokinetic strength test of involved and uninvolved elbow. Peak torque deficits of the flexor and extensors on the operated and non-operated side were below $20 \%$. They have found no significant impairment of elbow function. Pankaj et al. ${ }^{[16]}$ have used TRAP approach in $A O$ type $C$ distal humerus fractures $(n=40)$. They have reported that thirty-five patients $(87.5 \%)$ had good triceps strength, four patients $(10 \%)$ had fair strength, and one patient $(2.5 \%)$ had poor strength with an extension lag of 10 . In the current study, triceps rupture was not observed in any of the patients in which TRAP approach was performed. We found a decrease in the strength of the triceps in two and one patients in the TRAP and olecranon osteotomy groups, respectively. In a detailed examination of these patients, it was also observed that there was also weakness of the flexor muscles. We suggest that the muscle weakness may be related to the initial injury.

According to O'Driscoll et al., ${ }^{[12]}$ the ideal approach should provide adequate exposure, could be extended when required, should be as soft tissue dissection without osteotomy, the dissection should be in the plane between the nerve, all alternative surgical procedures should be applied with the same exposure, should allow early rehabilitation, and the possible revision should be performed with the same incision. The TRAP approach provides all these requirements. $[12,16,17]$ They have reported that TRAP approach provides sufficient exposure for open reduction and internal fixation, and also allows early rehabilitation. ${ }^{[12,25]}$ Furthermore, after TRAP exposure, there is a chance of total elbow prosthesis in the same session in cases in which the joint surface could not be restored. ${ }^{[12]}$

Restoration of elbow motion is one of the most important parameters in the treatment of intra-articular distal humerus fractures.[4-7] Athwal et al. ${ }^{[25]}$ compared the TRAP $(n=12)$ and olecranon osteotomy $(n=17)$ approach in the treatment of type $C$ distal humeral fractures. They found no significant difference between both groups in terms of flexion-extension arc, elbow flexion, elbow extension, pronation, supination, MEPS or DASH score. The authors stated that although they found no statistical difference between both groups, their subgroup analysis must be interpreted with caution because the study was not powered to detect such difference. In the study by Ozer et al.., ${ }^{[17]}$ range of motion in Type $\mathrm{Cl}$ and $\mathrm{C} 2$ $(n=9,82 \%)$ had an average of $116^{\circ}$ (range 95-140), and Type C3 $(n=2,18 \%)$ fractures had an average of $85^{\circ}$. In the study by Pankaj at al., ${ }^{[16]}$ the average of range of motion was $118 \pm 7$ degrees (range 80-140). In our study, the mean arc of motion was better in the TRAP group $\left(108^{\circ}\right.$ [range $70^{\circ}-140^{\circ}$ ] ) when compared to the olecranon osteotomy group $\left(98^{\circ}\right.$ [range $\left.\left.70^{\circ}-115^{\circ}\right]\right)$. The rate of type $\mathrm{C} 3$ fracture in our study was higher $(45.4 \%$, and $50 \%$ in the TRAP and olecranon osteotomy groups, respectively) than the study by Pankaj at al. ${ }^{[6]}$ $(\% 20)$ and Ozer et al. ${ }^{[17]}(18 \%)$, which may explain relatively lower mean arc of motion in our study. In the TRAP group, we used intact olecranon as a template for anatomic reconstruction of the joint. Therefore, we suggest that the use of olecranon joint surface as a template may provide better humero-trochlear joint congruency which may explain the high mean arc of motion in the TRAP group. In addition, the MEPS and q-DASH scores of our study are in line with the literature. ${ }^{[16,17,25]}$

Olecranon osteotomy has been associated with a number complications, including delayed union ${ }^{[14]}$ and $0 \%$ to $10 \%$ risk of nonunion. ${ }^{[8,27]}$ It was suggested that union problems observed in olecranon osteotomies are mostly related to the transverse osteotomy technique (30\%). ${ }^{[28]}$ Chevron shaped osteotomy reduced these complication. ${ }^{[8,14,29]}$ Chevron osteotomy increases contact surface that may promote healing, facilitate reduction and have inherent translational and rotational stability due to interlocking of the proximal and distal fragments. ${ }^{[8]}$ A study by Sanchez-Sotelo et al. ${ }^{[30]}$ have reported excellent and good results (79\%) using chevron type ostotomy in the treatment of complex distal humeral fractures. In the current study, an apex distal, chevron-shaped osteotomy was preferred in the olecranon osteotomy group. Union was observed in all patients. Although delayed union was observed in two patients (1I\%), healing was obtained without surgical intervention.

The need for a second operation to remove the implants used to repair olecranon osteotomy has been considered as in important shortcoming to the olecranon osteotomy. The risk of requiring subsequent hardware removal has been reported as $13 \%$ to $30 \%{ }^{[3-8]}$ Tak et al. ${ }^{[3]}$ have used olecranon osteotomy in ninety-four patients and stated that all the unsatisfactory results (average and poor) were seen in those patients who developed complications related to the olecranon osteotomy ( $p=0.000$, OR 103.2). In the current study, $22 \%$ of the patients had implant removal related to the symptom of implants used for olecranon osteotomy repair. In contrast, no patient had a second surgery in the TRAP group. Therefore, when considering a second surgery for implant removal, we suggested that the TRAP approach has a distinct advantage over the olecranon osteotomy approach.

The study has several limitations. Firstly, it is retrospective and comprises a relatively small number of patients. Secondly, 
parallel or orthogonal plating was used for fixation of distal humerus fractures in both groups. Thirdly, we could not make a comparison between sub-groups of the distal humerus fractures e.g. comminuted or osteoporotic fractures. Finally, we could not use isokinetic tests to evaluate the muscle strength. Future studies consisting of specific age groups, homogeneous sub-group types, with similar degree of osteoporotic bone can reveal more accurate results on indications and effectiveness of the TRAP and olecranon osteotomy approaches. Although olecranon osteotomy provides the best exposure, the effect of olecranon osteotomy on the development of osteoarthritis is not well- known. It should be evaluated in long term studies. We consider that the benefit of improved articular exposure must thus be weighed against this relatively high complication rates.

TRAP technique is superior to olecranon osteotomy in terms of average arc of elbow motion. We suggest that the TRAP approach is a successful alternative approach in the treatment of intra-articular distal humerus fractures that reduces reoperations and complications rates.

\section{Acknowledgements}

The authors declare no competing interest. No financial support was received for this paper.

Conflict of interest: None declared.

\section{REFERENCES}

1. Anglen J. Distal humerus fractures. J Am Acad Orthop Surg 2005;13:291-7.

2. Eralp L, Kocaoglu M, Sar C, Atalar AC. Surgical treatment of distal intraarticular humeral fractures in adults. Int Orthop 2001;25:46-50.

3. Gupta R, Khanchandani P. Intercondylar fractures of the distal humerus in adults: a critical analysis of 55 cases. Injury 2002;33:511-5.

4. Henley MB. Intra-articular distal humeral fractures in adults. Orthop Clin North Am 1987;18:11-23.

5. Hausman M, Panozzo A. Treatment of distal humerus fractures in the elderly. Clin Orthop Relat Res 2004;425:55-63.

6. Helfet DL, Schmeling GJ. Bicondylar intraarticular fractures of the distal humerus in adults. Clin Orthop Relat Res 1993;292:26-36.

7. Jupiter JB, Neff U, Holzach P, Allgöwer M. Intercondylar fractures of the humerus. An operative approach. J Bone Joint Surg Am 1985;67:22639.

8. Ring D, Gulotta L, Chin K, Jupiter JB. Olecranon osteotomy for exposure of fractures and nonunions of the distal humerus. J Orthop Trauma 2004;18:446-9.

9. Pajarinen J, Björkenheim JM. Operative treatment of type C intercondylar fractures of the distal humerus: results after a mean follow-up of 2 years in a series of 18 patients. J Shoulder Elbow Surg 2002;11:48-52.

10. Bryan RS, Morrey BF. Extensive posterior exposure of the elbow. A triceps-sparing approach. Clin Orthop Relat Res 1982;166:188-92.

11. Campbell WC. Incision for exposure of elbow joint. Am J Surg 1932;15;65-7.

12. O'Driscoll SW. The triceps-reflecting anconeus pedicle (TRAP) approach for distal humeral fractures and nonunions. Orthop Clin North
Am 2000;31:91-101.

13. Wilkinson JM, Stanley D. Posterior surgical approaches to the elbow: a comparative anatomic study. J Shoulder Elbow Surg 2001;10:380-2.

14. Chen G, Liao Q, Luo W, Li K, Zhao Y, Zhong D. Triceps-sparing versus olecranon osteotomy for ORIF: analysis of 67 cases of intercondylar fractures of the distal humerus. Injury 2011;42:366-70.

15. Li SH, Li ZH, Cai ZD, Zhu YC, Shi YZ, Liou J, et al. Bilateral plate fixation for type $\mathrm{C}$ distal humerus fractures: experience at a single institution. Int Orthop 2011;35:433-8.

16. Pankaj A, Mallinath G, Malhotra R, Bhan S. Surgical management of intercondylar fractures of the humerus using triceps reflecting anconeus pedicle (TRAP) approach. Indian J Orthop 2007;41:219-23.

17. Ozer H, Solak S, Turanli S, Baltaci G, Colakoğlu T, Bolukbasí S. Intercondylar fractures of the distal humerus treated with the triceps-reflecting anconeus pedicle approach. Arch Orthop Trauma Surg 2005;125:46974.

18. Mueller ME, Nazarian S, Koch P, Schatzker J, editors. The comprehensive classification of fractures of long bones. Berlin, Germany: SpringerVerlag; 1990. p. 100-1.

19. Gustilo RB, Anderson JT. Prevention of infection in the treatment of one thousand and twenty-five open fractures of long bones: retrospective and prospective analyses. J Bone Joint Surg Am 1976;58:453-8.

20. Wolfe SW, Ranawat CS. The osteo-anconeus flap. An approach for total elbow arthroplasty. J Bone Joint Surg Am 1990;72:684-8.

21. Turchin DC, Beaton DE, Richards RR. Validity of observer-based aggregate scoring systems as descriptors of elbow pain, function, and disability. J Bone Joint Surg Am 1998;80:154-62.

22. Hudak PL, Amadio PC, Bombardier C. Development of an upper extremity outcome measure: the DASH (disabilities of the arm, shoulder and hand) [corrected]. The Upper Extremity Collaborative Group (UECG) Am J Ind Med 1996;29:602-8.

23. O'Driscoll SW, Sanchez-Sotelo J, Torchia ME. Management of the smashed distal humerus. Orthop Clin North Am 2002;33:19-33.

24. Atalar AC, Demirhan M, Salduz A, Kiliçoğlu O, Seyahi A. Functional results of the parallel-plate technique for complex distal humerus fractures. [Article in Turkish] Acta Orthop Traumatol Turc 2009;43:21-7.

25. Athwal GS, Rispoli DM, Steinmann SP. The anconeus flap transolecranon approach to the distal humerus. J Orthop Trauma 2006;20:282-5.

26. Pierce TD, Herndon JH. The triceps preserving approach to total elbow arthroplasty. Clin Orthop Relat Res 1998;354:144-52.

27. Coles CP, Barei DP, Nork SE, Taitsman LA, Hanel DP, Bradford Henley $\mathrm{M}$. The olecranon osteotomy: a six-year experience in the treatment of intraarticular fractures of the distal humerus. J Orthop Trauma 2006;20:164-71.

28. Gainor BJ, Moussa F, Schott T. Healing rate of transverse osteotomies of the olecranon used in reconstruction of distal humerus fractures. J South Orthop Assoc 1995;4:263-8.

29. McKee MD, Kim J, Kebaish K, Stephen DJ, Kreder HJ, Schemitsch EH. Functional outcome after open supracondylar fractures of the humerus. The effect of the surgical approach. J Bone Joint Surg Br 2000;82:64651.

30. Sanchez-Sotelo J, Torchia ME, O'Driscoll SW. Complex distal humeral fractures: internal fixation with a principle-based parallel-plate technique. Surgical technique. J Bone Joint Surg Am 2008 Mar;90 Suppl 2 Pt 1:3146.

31. Tak SR, Dar GN, Halwai MA, Kangoo KA, Mir BA. Outcome of olecranon osteotomy in the trans-olecranon approach of intra-articular fractures of the distal humerus. Ulus Travma Acil Cerrahi Derg 2009;15:565-70. 
ORİIINAL ÇALIŞMA - ÖZET

\title{
İnterkondiler humerus kırıklarının tedavisinde triseps reflekting pedikül ve olekranon osteotomisi yaklaşımlarının karşılaştırılması
}

\section{Dr. İbrahim Azboy, ${ }^{1}$ Dr. Mehmet Bulut, ${ }^{1}$ Dr. Cahit Ancar, ${ }^{1}$ Dr. Abdullah Demirtaş, ${ }^{2}$ Dr. Emin Özkul, ${ }^{1}$ Dr. Mehmet Gem, ${ }^{1}$ Dr. Hilmi Karadeniz, ${ }^{3}$ Dr. Hüseyin Arslan ${ }^{1}$}

\begin{abstract}
${ }^{1}$ Dicle Üniversitesi Tıp Fakültesi, Ortopedi ve Travmatoloji Anabilim Dalı, Diyarbakır ${ }^{2}$ Göztepe Eğitim ve Araştırma Hastanesi, Ortopedi ve Travmatoloji Kliniği, İstanbul ${ }^{3}$ Bahçelievler Medikal Park Hastanesi, Ortopedi ve Travmayoloji Kliniği, İstanbul
\end{abstract}

AMAÇ: Eklem içi humerus alt uç kırıklarının tedavisinde triseps-reflekting ankoneus pedikül (TRAP) ve olekranon osteotomisi yöntemlerinin fonksiyonel sonuçları karşılaştıııldı.

GEREÇ VE YÖNTEM: Eklemi içi humerus kırığı olan 40 hasta geriye dönük olarak incelendi. Bunlardan 22 hastaya ( 12 erkek, 10 kadın; ortalama yaş 37.8 yıl dağıım 17-70) TRAP, I 8 hastaya (II erkek, 7 kadın; ortalama yaş 35.4 yıl dağılım I8-62) olekranon osteotomisi uygulandı. Kırık sınıflaması AO/ASIF sınıflamasına göre yapıldı. Fonksiyonel sonuçlar Mayo dirsek performans skoru ve Kol, Omuz ve El Engellilik (DASH) skoru ile değerlendirildi.

BULGULAR: Triseps-reflekting ankoneus pedikül grubunda dirsek eklem hareket açıklığı ortalama $108^{\circ}$ (dağılım $\left.40^{\circ}-140^{\circ}\right)$ iken olekranon osteotomisi grubunda ortalama $98^{\circ}$ (dağıım $70^{\circ}-115^{\circ}$ ) bulundu. Eklem hareket açıklığı bakımından iki grup arasında istatiksel olarak anlamlı fark bulundu $(p=0.038)$. Her iki grup arasında DASH ve MEPS puanı bakından istatiksel olarak anlamlı fark saptanmadı $(p=0.412, p=201$, sırasıyla). Komplikasyon oranları TRAP grubunda \%27.2 iken olekranon osteotomisi grubunda \%55 bulundu.

TARTIŞMA: Triseps-reflekting ankoneus pedikül yöntemi, olekranon osteotomisine göre dirsek eklem hareket açıklığını sağlamada daha başarılıdır. Ayrıca TRAP yöntemi komplikasyon oranlarını ve yeniden ameliyat gereksinimini azaltmaktadır.

Anahtar sözcükler: Eklemiçi kırık; humerus alt uç; internal tespit; TRAP; olekranon osteotomisi.

Ulus Travma Acil Cerrahi Derg 2016;22(1):58-65 doi: 10.5505/tjtes.2015.42948 